\title{
Human adipose beiging in response to cold and mirabegron
}

Brian S. Finlin, ${ }^{1}$ Hasiyet Memetimin, ${ }^{1}$ Amy L. Confides, ${ }^{2}$ Ildiko Kasza, ${ }^{3}$ Beibei Zhu, ${ }^{1}$ Hemendra J. Vekaria, ${ }^{4,5}$ Brianna Harfmann, ${ }^{1}$ Kelly A. Jones, ${ }^{1}$ Zachary R. Johnson, ${ }^{1}$ Philip M. Westgate, ${ }^{6}$ Caroline M. Alexander, ${ }^{3}$ Patrick G. Sullivan, ${ }^{4,5}$ Esther E. Dupont-Versteegden, ${ }^{2}$ and Philip A. Kern'

'The Department of Internal Medicine, Division of Endocrinology, and the Barnstable Brown Diabetes and Obesity Center, and ${ }^{2}$ Department of Rehabilitation Sciences, College of Health Sciences and Center for Muscle Biology, University of Kentucky, Lexington, Kentucky, USA. ${ }^{3}$ McArdle Laboratory for Cancer Research, School of Medicine and Public Health, University of Wisconsin-Madison, Madison, Wisconsin, USA. ${ }^{4}$ Department of Neuroscience, ${ }^{5}$ Spinal Cord and Brain Injury Research Center, and ${ }^{6}$ College of Public Health, University of Kentucky, Lexington, Kentucky, USA.

BACKGROUND. The induction of beige adipocytes in s.c. white adipose tissue (WAT) depots of humans is postulated to improve glucose and lipid metabolism in obesity. The ability of obese, insulin-resistant humans to induce beige adipose tissue is unknown.

METHODS. We exposed lean and obese research participants to cold (30-minute ice pack application each day for 10 days of the upper thigh) or treated them with the $\beta 3$ agonist mirabegron. We determined beige adipose marker expression by IHC and quantitative PCR, and we analyzed mitochondrial bioenergetics and UCP activity with an Oxytherm system.

RESULTS. Cold significantly induced UCP1 and TMEM26 protein in both lean and obese subjects, and this response was not associated with age. Interestingly, these proteins increased to the same extent in s.c. WAT of the noniced contralateral leg, indicating a crossover effect. We further analyzed the bioenergetics of purified mitochondria from the abdominal s.c. WAT of cold-treated subjects and determined that repeat ice application significantly increased uncoupled respiration, consistent with the UCP1 protein induction and subsequent activation. Cold also increased State 3 and maximal respiration, and this effect on mitochondrial bioenergetics was stronger in summer than winter. Chronic treatment (10 weeks; 50 mg/day) with the $\beta 3$ receptor agonist mirabegron induces UCP1, TMEM26, CIDEA, and phosphorylation of HSL on serine ${ }^{660}$ in obese subjects.

CONCLUSION. Cold or $\beta 3$ agonists cause the induction of beige adipose tissue in human s.c. WAT; this phenomenon may be exploited to increase beige adipose in older, insulin-resistant, obese individuals.

TRIAL REGISTRATION. Clinicaltrials.gov NCT02596776, NCT02919176.

FUNDING. NIH (DK107646, DK112282, P20GM103527, and by CTSA grant UL1TR001998).

Authorship note: BSF, HM, and ALC contributed equally to this work.

Conflict of interest: The authors declare that no conflict of interest exists.

Submitted: April 6, 2018

Accepted: July 3, 2018

Published: August 9, 2018

Reference information: JCI Insight. 2018;3(15):e121510. https://doi.org/10.1172/jici. insight.121510.

\section{Introduction}

The primary function of s.c. white adipose tissue (WAT) is to store fat in unilocular adipocytes. However, in response to cold or $\beta$-adrenergic agonists, UCP1-expressing adipocytes form in white adipose depots (reviewed in ref. 1). These adipocytes are called beige adipocytes due to their unique properties, anatomical location, and developmental origin $(2,3)$. Beige adipocytes are functionally related to brown adipocytes, which dissipate energy in the form of heat. In addition to thermogenesis, energy dissipation allows brown adipose tissue (BAT) to protect against obesity in rodents (4-6). Whether recruitment of BAT or beige adipose can be utilized as an antiobesity therapy in humans is an open question (7). In addition to thermogenesis and energy expenditure, brown and beige adipose tissue are associated with improved glucose and lipid homeostasis and improved insulin sensitivity $\left(\mathrm{S}_{\mathrm{T}}\right)$ in humans and mice (8-17). Thus, there is tremendous interest in strategies to recruit and activate brown and beige adipose tissue to counteract the detrimental metabolic effects of obesity $(1,3)$. 
Studies in rodents indicate that cold strongly induces beige adipose in s.c. WAT depots, and recent studies have begun to address the induction of beige adipose in humans in response to a variety of stimuli $(1,3$, $18,19)$. Baseline expression of UCP1 is low in human s.c. WAT. We have reported that mRNA expression of UCP1 and the beige adipose marker TMEM26 are induced by acute cold and by seasonal exposure, and we have reported that this induction is inhibited by obesity and inflammation $(18,19)$. This is consistent with studies demonstrating that BAT detected by PET CT is less in obese subjects (20-22). A study by Chondronikola et al. reported that UCP1 protein expression in abdominal s.c. WAT is higher in research participants in which BAT was detected by PET CT scans (10). Exercise may induce beiging in humans (recently reviewed in ref. 23). However, the strongest beiging of human WAT occurs in disease states such as severe burn or in cancer patients with cachexia or pheochromacytoma (24-27). These studies clearly indicate that human s.c. WAT has the potential for beiging. However, strategies to induce beige adipose in humans with metabolic disease to improve glucose and lipid homeostasis are currently lacking.

In this study, we characterized the ability of s.c. WAT from lean and obese insulin-resistant human subjects to beige in response to physiologic, localized cold, which consisted of repeated, 30-minute per day cold exposure by applying an ice pack to the thigh or abdomen for 10 consecutive days. We quantified beiging by measuring the protein and mRNA expression of UCP1 and TMEM26, along with mitochondrial bioenergetics, and determined whether baseline $\mathrm{S}_{\mathrm{I}}$, BMI, age, or sex predicted the beiging response. Since obese subjects increased beiging in response to cold, we investigated whether we could induce beiging in obese subjects with chronic treatment (10 weeks; $50 \mathrm{mg}$ per day) with mirabegron, a $\beta 3$ receptor that acutely stimulates BAT in lean men (28).

\section{Results}

Repeated cold exposure upregulates UCP1 and TMEM26 expression in s.c. WAT. We previously reported that a single, 30-minute cold exposure induces UCP1 and TMEM26 mRNA expression in the thigh of lean subjects (19). Here, we wanted to determine whether repeated cold exposure increases UCP1 and TMEM26 protein expression and whether this is inhibited in obese, insulin-resistant subjects or is influenced by other factors such as age or sex. Indeed, our previous work indicated that seasonal induction of UCP1 in s.c. WAT is inhibited in obese subjects (19), and other studies on BAT in humans have found that it diminishes with age (20-22). This study was conducted in the summer because our previous work suggested that lean subjects have increased UCP1 in winter; therefore, responsiveness would be higher in the summer (19). The baseline characteristics of the research participants are given in Table 1. As expected, the lean research participants had a lower BMI and were more insulin sensitive than the obese, and they had lower fasting glucose and trigylcerides $(P<0.01)$, and higher HDL $(P<0.05)$, than the obese subjects (Table 1).

We performed biopsies to obtain thigh s.c. WAT at baseline and after 10 days of a 30-minute treatment per day with an ice pack in both the iced (cold) and the contralateral legs. This study design allowed us to address the effect of cold and the potential response to activation of the sympathetic nervous system (SNS). A portion of the biopsies was used for analysis of gene expression, and the remainder was fixed and used for IHC. We note that 5 of the subjects in this study applied ice to their thigh and abdomen since they were part of the mitochondrial bioenergetics study described below. S.c. WAT UCP1 mRNA expression increased in the leg exposed to cold in the lean subjects (Figure $1 \mathrm{~A} ; P<0.05$ ). However, this mRNA response to cold in the iced leg was blunted in obese subjects, demonstrating a significant difference in the ability of lean and obese subjects to induce UCP1 mRNA expression (Figure 1A; response of lean versus obese in cold treated leg, $P<0.05)$. UCP1 mRNA expression increased in the contralateral leg of lean subjects, but the increase failed to reach statistical significance $(P=0.11)$.

Next, we analyzed UCP1 protein expression by IHC. We determined the area of UCP1 staining and normalized it to the number of adipocytes in the field, since this study involved lean and obese research participants. Figure 1, B and C, show representative images of lean and obese subjects, respectively, and the results are quantified in Figure 1D. Cold treatment increased UCP1 protein staining 2-fold in s.c. WAT of both the cold-treated and the contralateral leg in lean subjects (Figure 1D; cold, $P<0.0001$; contralateral, $P<0.0001)$. Cold induced UCP1 protein expression in the s.c. WAT of obese subjects, and there was a trend for induction of UCP1 in s.c. WAT of the contralateral leg (Figure 1D; cold, $P<0.01$; contralateral leg, $P<0.1$ ). The induction of UCP1 protein was different than the induction of UCP1 mRNA, which was inhibited in obese subjects (Figure 1A). 
Table 1. Baseline characteristics of study subjects.

\begin{tabular}{|c|c|c|c|c|}
\hline Study ${ }^{A}$ & Cold Study Lean Subjects & Cold Study Obese Subjects & $P^{B}$ & $\begin{array}{c}\text { Mirabegron study obese } \\
\text { subjects }\end{array}$ \\
\hline $\begin{array}{l}\text { Number } \\
\text { (Sex, M/F) }\end{array}$ & $\begin{array}{c}17 \\
(6 / 11)\end{array}$ & $\begin{array}{c}9 \\
(3 / 6)\end{array}$ & & $\begin{array}{c}6 \\
(1 / 5)\end{array}$ \\
\hline BMI & $24.3 \pm 0.6$ & $36.1 \pm 1.2$ & 0.001 & $34.5 \pm 1.5$ \\
\hline$S_{1}$ (Matsuda) & $5.6 \pm 0.7^{c}$ & $2.3 \pm 0.3$ & $<0.0001$ & $3.2 \pm 0.5$ \\
\hline Disposition index & $6.1 \pm 1.1^{\complement}$ & $2.9 \pm 0.5$ & 0.008 & $2.8 \pm 0.4$ \\
\hline Fasting glucose & $82.8 \pm 1.6^{c}$ & $100.7 \pm 6.7$ & 0.008 & $98 \pm 4$ \\
\hline $\mathrm{TG}(\mathrm{mg} / \mathrm{dl})$ & $100.6 \pm 21.4^{c}$ & $175.1 \pm 35$ & $0.0024^{D}$ & $97 \pm 14$ \\
\hline Cholesterol (mg/dL) & $183.6 \pm 8.4^{c}$ & $198.3 \pm 16.3$ & 0.40 & $202 \pm 11$ \\
\hline HDL (mg/dL) & $62.1 \pm 5.0^{c}$ & $46.8 \pm 2.6$ & 0.02 & $56 \pm 8$ \\
\hline LDL (mg/dL) & $101.4 \pm 7.4^{c}$ & $111.9 \pm 10.9 \mathrm{E}$ & 0.40 & $126 \pm 6$ \\
\hline
\end{tabular}

${ }^{A}$ Data are presented as mean \pm SEM. ${ }^{B}$ A two-tailed Student's $t$ test was performed on cold-study lean versus obese research participants $(n=17$ lean; $n=9$ obese) except where indicated. ${ }^{C} n=12$. ${ }^{D}$ Mann-Whitney $U$ test. ${ }^{E} n=8$. TG, triglyceride.

We also evaluated TMEM26, a marker of beige adipocytes (2). TMEM26 mRNA expression increased in the s.c. WAT of the leg exposed to cold $(P<0.01)$ and of the contralateral leg $(P<0.05)$ of the lean subjects, but TMEM26 mRNA expression did not increase in the obese subjects (Figure 2A). TMEM26 protein staining in the s.c. WAT of the cold-treated leg $(P<0.0001)$ and the contralateral leg $(P<0.001)$ in lean subjects was higher than baseline (Figure 2, B-D). TMEM26 staining also increased in the s.c. WAT of the cold-treated leg $(P<0.001)$ and the contralateral leg $(P<0.05)$ in obese subjects (Figure 2, B-D). Further analysis of the data indicated that TMEM26 expression increased more in the cold-treated leg of the obese subjects than the lean subjects $(P=0.014)$. Overall, the pattern of induction of TMEM26 (Figure 2 ) is consistent with the pattern of induction of UCP1 by cold (Figure 1).

Analysis of the UCP1 staining pattern indicated that UCP1 was expressed in cells other than adipocytes - possibly vascular structures. Therefore, we costained UCP1 with endothelial cell markers. As shown in Figure 3, A and B, there is some UCP1 costaining with CD31 and lectin, in addition to adipocytes, which is revealed by a crescent-shaped pattern around unilocular adipocytes. Figure $3 \mathrm{C}$ shows an image in which signal in the green channel is increased to show the outline of the adipocytes. This demonstrates UCP1 staining in adipocytes in curved or crescent-shaped structures, as well as smaller punctate structures (arrows point to examples of UCP1 associated with adipocytes in these patterns).

In summary, several interesting and unexpected findings were revealed by the immunohistochemical characterization of UCP1 and TMEM26 expression in response to cold. These proteins were increased to the same extent in s.c. WAT of contralateral leg as the cold-treated leg, suggesting that icing 1 leg activates a crossover effect, which we postulate is mediated by the SNS. We initially hypothesized that the beiging response to cold would be inhibited in obese subjects because we previously observed that seasonal induction of UCP1 mRNA was blunted in obese subjects (19). However, the obese subjects induced beige protein markers equally as well as the lean subjects, indicating that beiging could potentially be exploited therapeutically in obese subjects with metabolic disease.

Relationship between s.c. WAT beiging and $S_{p}$ BMI, age, and sex. We performed regression analysis to determine whether $\mathrm{S}_{\mathrm{I}}$, BMI, or age predicted the increase of UCP1 or TMEM26 protein expression by repeated cold exposure. As shown in Figure 1D, UCP1 protein was induced in both lean and obese subjects. Consistent with this, neither baseline Matsuda Index, homeostatic model assessment of insulin resistance (HOMAIR), nor BMI predicted the change in UCP1 protein in either leg. The age range of these subjects was 21-64 years old, and age did not predict the change in UCP1 by cold. The correlations between age, BMI, Matsuda index, and the change in UCP1 in s.c. WAT of the cold-treated leg are shown in Figure 4, A-C. Finally, there was no effect of sex on UCP1 protein induction (cold, $P=0.52$; contralateral, $P=0.56$ ).

We repeated this analysis on the induction of TMEM26 protein expression and had similar findings. Cold induced TMEM26 protein staining in s.c. WAT in the iced leg of obese subjects more than the lean 
A

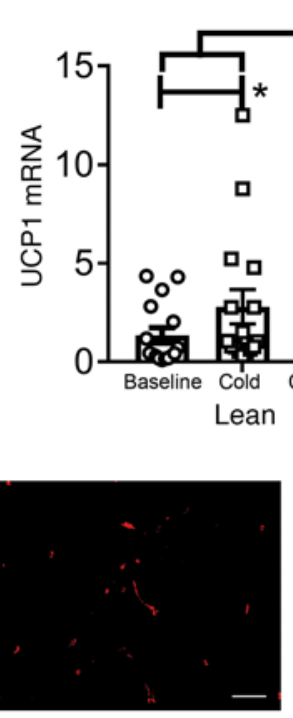

C

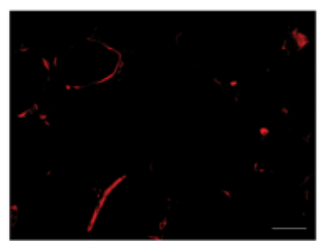

Baseline

B
- Baseline

a Cold

$\Delta$ Contralateral

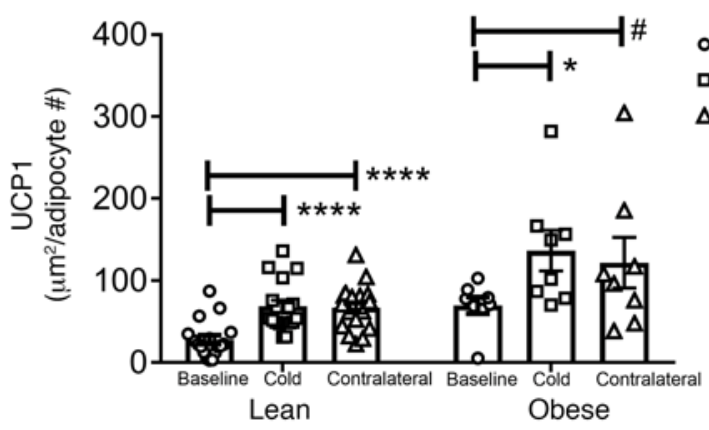

D

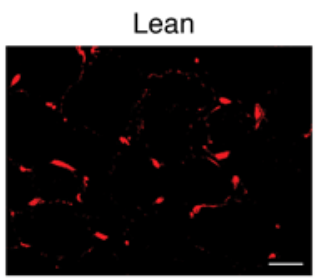

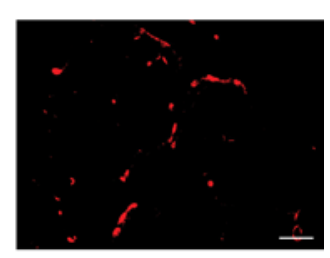

Obese

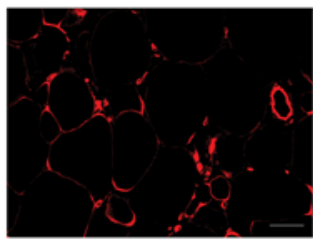

Cold

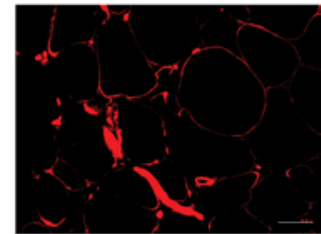

Contralateral
Cold Contralateral

Obese

Baseline

a Cold

$\Delta$ Contralateral
Figure 1. Repeated cold exposure induces uncoupling protein 1 (UCP1) in human thigh s.c. white adipose tissue (WAT). An ice pack was applied to the thigh for 30 minutes each day for 10 consecutive days. S.c. WAT was isolated and subjected to mRNA analysis and UCP1 IHC as described in Methods. (A) UCP1 mRNA expression was determined in lean $(n=16)$ and obese $(n=8)$ biopsies. (B and $\mathbf{C})$ adipose tissue sections $(10 \mu \mathrm{m})$ were stained with rabbit anti-UCP1 antibody; a representative image of UCP1 staining at baseline and after 10 days of icing in the iced and contralateral legs of a lean (B) and obese (C) subjects is shown. Scale bars: $50 \mu \mathrm{m}$. (D) UCP1 staining was quantified in the lean $(n=17)$ and obese $(n=8)$ subjects. The data are expressed as area of UCP1 staining $\left(\mu \mathrm{m}^{2}\right)$ per adipocyte number. The data were analyzed by a repeated-measures one-way MANOVA as described in Methods. Data represent mean \pm SEM; ${ }^{*} P<0.05 ;{ }^{* * * *} P<0.0001 ;{ }^{*} P<0.1$.

subjects (Figure 2D). Consistent with this, the increase in TMEM26 protein was negatively correlated with the Matsuda Index and positively correlated with BMI in the cold-treated leg (Figure 4, D-F). As with UCP1, age did not predict the change in TMEM26 protein. Also, there was no significant effect of sex on TMEM26 protein induction. However, we did find a trend for males (all subjects combined) to have a greater increase in TMEM26 protein staining after cold than females (cold, $P=0.07$; contralateral, $P=0.12$; data not shown).

Cold and mitochondrial bioenergetics. Since cold increased UCP1 protein, we next determined whether this had functional consequences on mitochondria. We purified mitochondria from abdominal s.c. WAT of 11 lean subjects (Supplemental Table 1; supplemental material available online with this article; https:// doi.org/10.1172/jci.insight.121510DS1) before and after 10 days of repeated cold exposure, which consisted of applying an ice pack to 1 side of the abdomen and the thigh, and analyzed the bioenergetics in an Oxytherm system; we did not perform contralateral abdominal biopsies for this study. Cold increased UCP1 and TMEM26 protein staining in abdominal s.c. WAT (Supplemental Figure 1) in a manner similar to thigh (Figures 1 and 2). An example recording of mitochondrial bioenergetics before and after cold is shown in Figure 5A. This protocol allowed us to assess State 3 and State 4 respiration, UCP-associated uncoupled respiration, and maximal uncoupled respiration (Figure 5). This procedure was conducted in the winter $(n=6)$ and summer $(n=5)$, and the results are analyzed altogether (Figure 5$)$ and by season (Figure 6). There were no significant differences in the age or BMI of the summer and winter subjects (Supplemental Table 1), and these subjects were similar to the lean subjects in the cold study (Table 1). 
A

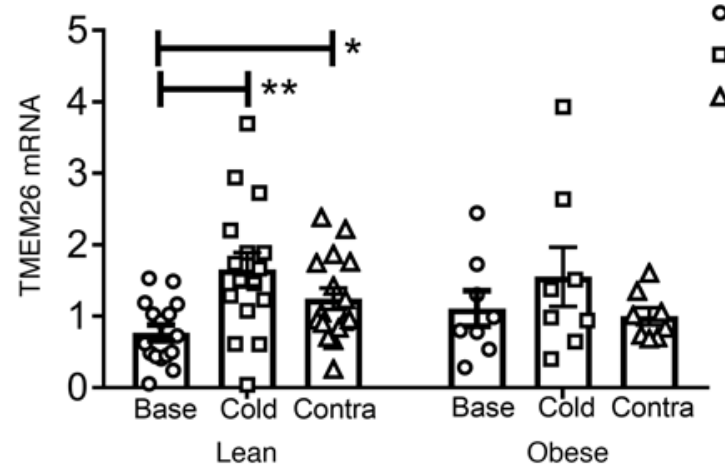

B

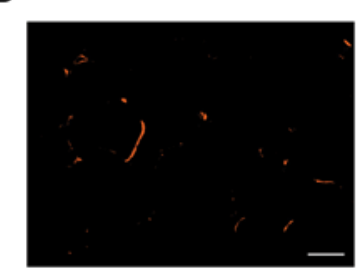

C

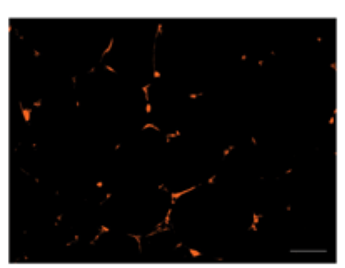

Baseline

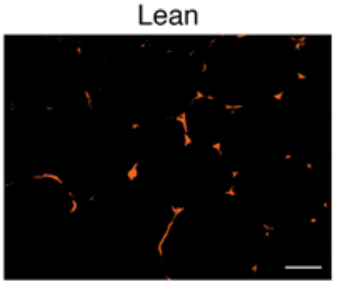

Obese

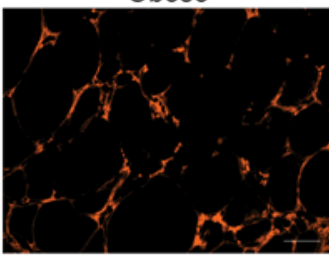

Cold
- Baseline

a Cold

$\Delta$ Contralateral
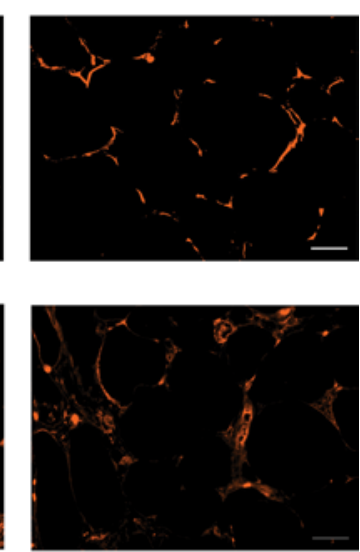

Contralateral

Figure 2. Repeated cold exposure induces transmembrane protein 26 (TMEM26) in human thigh s.c. white adipose tissue (WAT). S.c. WAT described in

Figure 1 was isolated and subjected to mRNA analysis and TMEM26 IHC. (A) TMEM26 mRNA expression was determined in lean $(n=16)$ and obese $(n=8)$ biopsies. (B and C) Adipose tissue sections $(10 \mu \mathrm{m})$ were stained with rabbit anti-TMEM26 antibody; a representative image of TMEM26 staining at baseline and after 10 days of icing in the iced and contralateral legs of a lean (B) and obese (C) subject is shown. Scale bars: $50 \mu \mathrm{m}$. (D) TMEM26 staining was quantified in the lean $(n=17)$ and obese $(n=8)$ subjects. The data are expressed as area of TMEM26 staining $\left(\mu \mathrm{m}^{2}\right)$ per adipocyte number. The data were analyzed by a repeated-measures one-way MANOVA as described in Methods. Data represent mean \pm SEM; ${ }^{*} P<0.05 ;{ }^{* *} P<0.01 ;{ }^{* *} P<0.001$; **** $P<0.0001$.

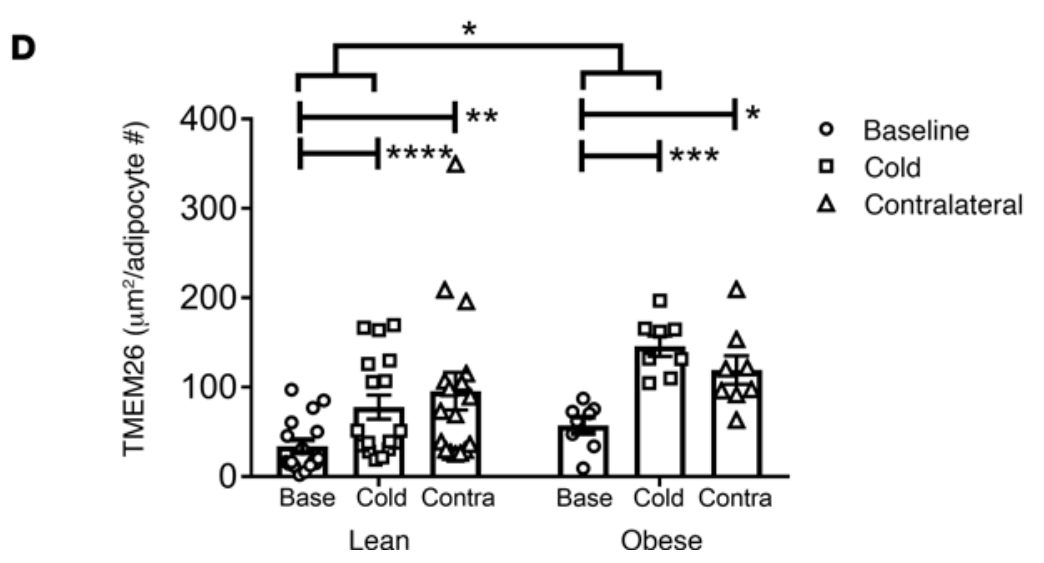

Figure 5, A-C, shows that the addition of free fatty acid (FFA), after induction of State 4 respiration by oligomycin (Oligo), stimulates the oxygen consumption rate (OCR), and the subsequent addition BSA reverses this activation. This result is consistent with the activation of UCP1, which requires FFAs. As shown in Figure 5D, 10 days of cold increased uncoupled respiration $(P=0.05)$, which was defined as the difference between the Oligo and FFA OCRs. There was a trend for cold to increase maximal respiration, which was defined as the difference between the Oligo and FCCP OCRs (Figure 5E; $P=0.06$ ). These data show that mitochondrial uncoupling function is enhanced in response to cold, consistent with the induction of UCP1.

As indicated above, the abdominal s.c. WAT biopsies used in Figure 5 were performed in the summer $(n=5)$ and winter $(n=6)$. Since we and others have shown that there are seasonal differences in UCP1 mRNA expression (19), we analyzed the effect of cold on mitochondrial bioenergetics by season (Figure 6, A-D). Surprisingly, there were no differences in the baseline OCRs in the summer and winter (Figure 6, A and C). The data presented in Figure 6, A-D, suggest that cold had a greater effect on mitochondrial bioenergetics in the summer than in the winter. In the summer, cold significantly increased the State 3 


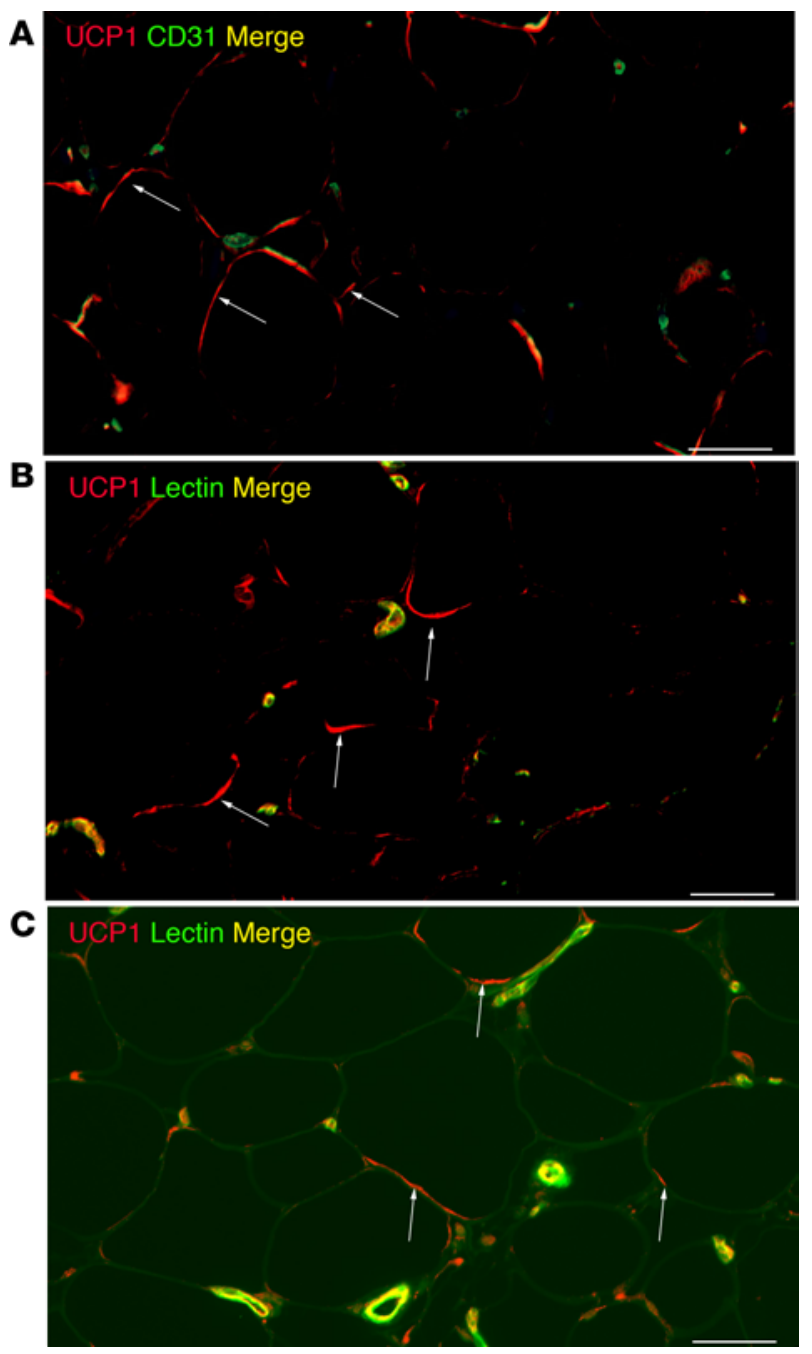

Figure 3. Localization of uncoupling protein 1 (UCP1) in s.c. white adipose tissue (WAT). S.c. WAT from a cold-treated leg described in Figure 1 was stained with rabbit anti-UCP1 and cluster of differentiation 31 (CD31) (A) or lectin (B). (C) Green autofluorescence demonstrates the outline of adipocytes. Arrows point to UCP1 localized to adipocytes. Scale bars: $50 \mu \mathrm{m}$. This is a representative image of an experiment done on obese and lean subjects $(n=3)$.

OCR (Figure 6E; $P<0.05$ ), there was a trend for increased uncoupled respiration (Figure 6F; $P=0.06$ ), and cold significantly increased maximal respiration (Figure 6G; $P<0.05$ ). None of these parameters were increased by 10 days of acute cold exposure in the winter. To further analyze these data, we determined the change in the OCR caused by cold in the summer and winter. This analysis indicated that the change in the State 3 OCR and maximal respiration OCR was significantly higher in the summer than winter (Figure $6, \mathrm{H}$ and I; $P<0.05$ ). Overall, these data suggest that cold stimulates multiple aspects of mitochondrial bioenergetics more in the summer than winter.

Mirabegron upregulates UCP1, TMEM26, and CIDEA in obese, insulin-resistant subjects. The results presented in Figures 1 and 2 suggest that the beiging response of obese subjects to cold is similar to lean subjects and that there is potential involvement of the SNS, since there was a crossover effect on the contralateral (noniced) side (Figure 1D and Figure 2D). Because there is tremendous interest in therapeutic strategies to induce beige adipocytes and UCP1 in white adipose depots of obese subjects to treat metabolic disease, we tested the ability of mirabegron, a $\beta 3$-agonist approved for the treatment of overactive bladder, to induce UCP1 in obese, insulin-resistant individuals. The baseline characteristics of these research participants are given in Table 1. Treatment with mirabegron for 10 weeks was well tolerated, and there was no change in weight, blood pressure, or heart rate (Supplemental Table 2). Abdominal s.c. WAT biopsies were performed before and after 10 weeks of mirabegron treatment. Mirabegron treatment increased UCP1 protein levels 3-fold (Figure 7, A and B; $P<0.001$ ), TMEM26 8.7-fold (Figure 7, C and $\mathrm{D} ; P<0.01$ ), and CIDEA 3.4-fold (Figure 7, E and F; $P<0.05$ ). These results clearly indicate that mirabegron induces the expression of UCP1 and beige adipocyte markers to a higher degree than 10 days of repeated cold exposure (Figures 1 and 2). 
A
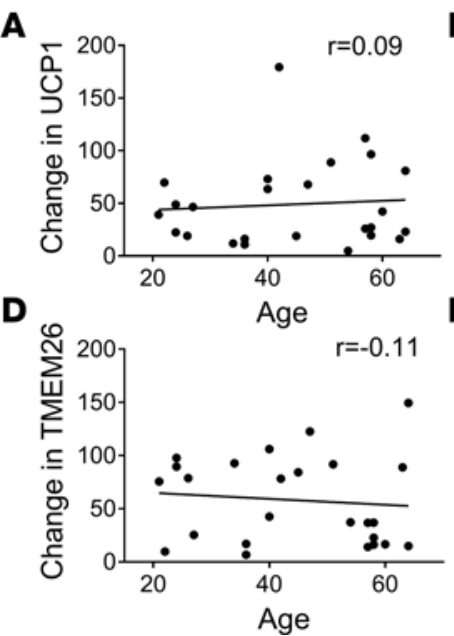

B
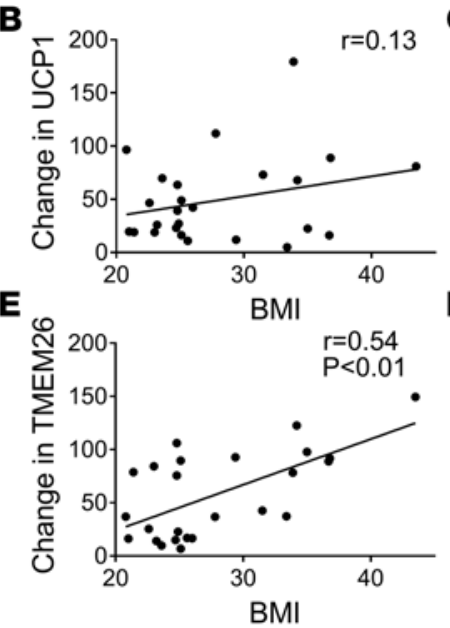
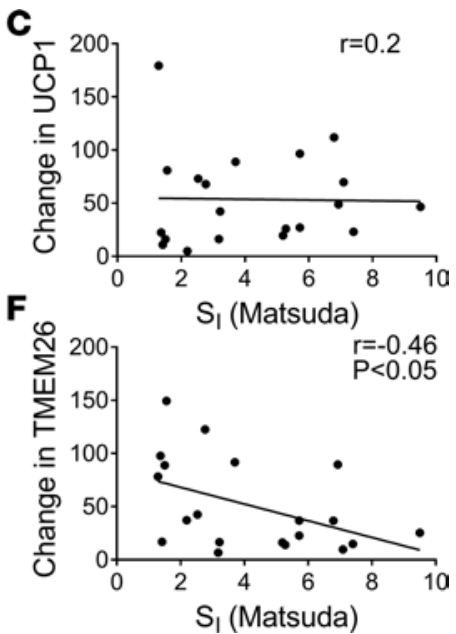

Figure 4. Regression analysis of the beiging response to cold with age, BMI, and insulin sensitivity (5). The change in uncoupling protein 1 (UCP1) and transmembrane protein 26 (TMEM26) staining in s.c. white adipose tissue of the cold-treated leg was calculated (cold-baseline). Regression analysis of the change in UCP1 (A-C) and TMEM26 (D-F) staining versus age $(n=25)$, BMI $(n=25)$, and S, (Matsuda Index; $n=20)$ is shown. Spearman correlation coefficients and significant $P$ values from unpaired, two tailed student's t-tests are indicated.

To further explore the mechanism of mirabegron effects, we examined other events expected to be activated in adipocytes by $\beta 3$ receptor agonism. As shown in Figure $8, \mathrm{~A}$ and $\mathrm{B}$, mirabegron treatment induced phosphorylation of HSL $\operatorname{serine}^{660}(P<0.05)$, a residue phosphorylated by protein kinase A (PKA) that stimulates HSL activity, suggesting that mirabegron activates cAMP-protein kinase A signaling. There was considerable colocalization of phospho-HSL serine ${ }^{660}$ staining with perilipin in unilocular adipocytes, indicating that HSL activation occurs in adipocytes (Supplemental Figure 2, A and B). Supplemental Figure 2, C and D, also show phospho-HSL serine ${ }^{660}$ staining in wheat germ agglutinin-positive areas, suggesting HSL activation in endothelial cells of capillaries and vessels. HSL serine ${ }^{565}$ phosphorylation, which inhibits HSL activation, was not significantly increased (Figure $8 \mathrm{C}$ ). Peroxisome proliferator-activated receptor gamma coactivator 1 -alpha (PGC1 $\alpha$ ) is important for beiging since it functions as a coactivator of PPAR $\alpha$ to induce UCP1 and upregulates mitochondrial biogenesis (29-30). In rodents PGC1 $\alpha$ is induced by $\beta A R$ activation (31); however, we found that PGC1 $\alpha$ was not induced by mirabegron treatment at the mRNA (Figure 8D) or the protein (Figure 8E) levels (uncropped blots for the Figure 8E inset are shown in Supplemental Figure 3). Consistent with this, mirabegron treatment did not increase mitochondrial DNA (mtDNA) content (Figure 8F). Thus, PGC1 $\alpha$, which is an important regulator of the beiging response, is not increased by mirabegron treatment in obese humans. Finally, we were unable to detect PRDM16, another protein that increases UCP1 expression, by immunoblotting in s.c. WAT either before or after mirabegron treatment.

Summary and conclusions. In summary, this study clearly shows that the protein expression of UCP1 and TMEM26 is induced in human s.c. WAT by cold and a selective $\beta 3$ agonist. Unexpectedly, we found that icing 1 leg resulted in an equivalent beiging response in the contralateral leg, suggesting that contact of a relatively small area, the thigh of 1 leg, with cold for a short duration stimulates the SNS. This study included research participants with a wide range of BMIs, $\mathrm{S}_{\mathrm{I}}$, and age, and our analysis indicated that neither these factors nor sex affected the beiging response. Mirabegron treatment increased the expression of UCP1 and TMEM26 in obese subjects; however, the failure to induce PGC1 $\alpha$ by mirabegron treatment in obese subjects may limit the beiging process. These studies clearly indicate the potential of s.c. WAT of obese, insulin-resistant humans to beige.

\section{Discussion}

Beige adipocytes are readily induced in WAT in rodents by cold and $\beta$-adrenergic receptor agonists, and this improves glucose and lipid metabolism. Previously, we found that UCP1 mRNA expression is increased in the winter in lean humans and that this is blunted by obesity (19). Furthermore, human BAT is detected less with obesity and age (20-22). On the basis of these previous studies, we hypothesized that the beiging 
$\mathbf{A}$
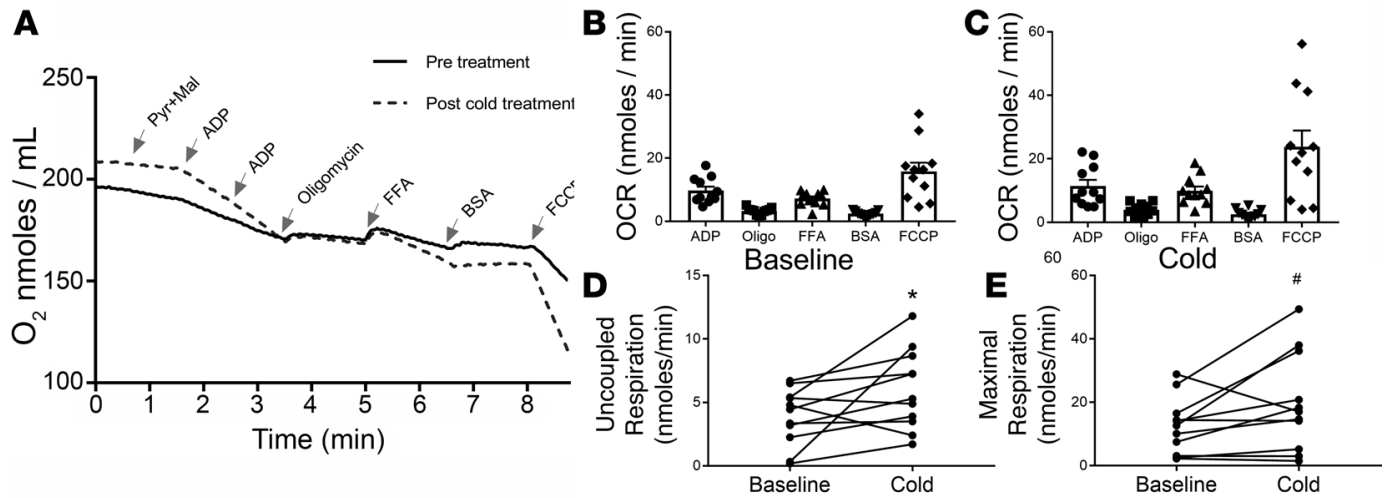

Figure 5. Cold stimulates s.c. white adipose tissue (WAT) mitochondrial bioenergetics. (A) Abdominal s.c. WAT was isolated from subjects before and after cold exposure, mitochondria were purified, and the bioenergetics were analyzed using an Oxytherm system as described in Methods. An example trace shows the $\mathrm{O}_{2}$ level in the chamber during the course of the experiment for 1 subject before and after cold exposure. The substrates pyruvate (Pyr) and malate (Mal), adenosine diphosphate (ADP), oligomycin (Oligo), free fatty acid (FFA; 60 uM linoleic acid), fatty acid free BSA, and trifluoromethoxy carbonylcyanide phenylhydrazone (FCCP; $10 \mu \mathrm{m})$ were sequentially added at the indicated times. The oxygen consumption rate (OCR; nmoles/min) was determined during each step. (B and C) Analysis of mitochondrial bioenergetics before and after 10 days of repeated cold exposure. (D) Uncoupled respiration was determined by calculating the difference between the Oligo and FFA OCRs. (E) Maximal respiration was calculated by determining the difference between Oligo and FCCP OCRs. Data are represented as mean \pm SEM $(n=11)$. The data were analyzed by a paired, 2 -tailed student's $t$ test; ${ }^{*} P<0.05 ;{ }^{\#} P<0.1$.

response to repeated cold exposure would be impaired in obese, insulin-resistant subjects and in older subjects. However, we found that the beiging response is not inhibited in either obese or older subjects. These findings may be highly significant since older, obese humans with metabolic disease would be the most clinically relevant target for therapies to increase beige adipose tissue.

Cold treatment induced UCP1 and TMEM26 protein expression to the same extent in the s.c. WAT from the contralateral limb as the leg directly exposed to cold, suggesting that cold stimulation of $1 \mathrm{limb}$ can systemically activate the SNS. Little is known about the amount of stimulus dosing (i.e., how much surface are must be exposed to cold and for how much time) is necessary to activate the SNS in humans, but a recent paper also observed a crossover effect mediated by the SNS in humans using a cold water immersion protocol (32). We and others have reported cell autonomous induction of UCP1 by cold using in vitro adipocyte cell culture models $(19,33)$, and therefore, we expected that the cold-treated leg would have had more UCP1 induction than the contralateral leg, an effect independent of the SNS. In this study, the biopsies were performed the day after the last cold treatment, and thus, there was time for any additional cold-mediated response in the cold-treated leg to diminish, possibly explaining the equal response that we observed. In a recent study, 10-day, whole-body exposure to cold $\left(14^{\circ} \mathrm{C}-15^{\circ} \mathrm{C}\right)$ for up to 6 hours per day increased $\mathrm{S}_{\mathrm{I}}$ in diabetic subjects (17). It would be interesting to determine whether our protocol, which involves short-term exposure of a limited skin area to cold, would also enhance $\mathrm{S}_{\mathrm{I}}$.

We were surprised that UCP1 protein increased to the same extent in obese subjects as lean after cold exposure because our previous study on UCP1 mRNA indicated that seasonal upregulation of UCP1 mRNA was blunted in obese subjects (19). Consistent with this observation, induction of UCP1 mRNA was blunted in obese subjects (Figure 1A), even though UCP1 protein was induced. One explanation for the difference in UCP1 mRNA and protein expression in Figure 1 is that there may have been a transient increase in UCP1 mRNA in the obese subjects during the response to cold, which was gone by the time of biopsy. Indeed, the half-life of UCP1 protein is longer than the mRNA half-life (34). This, and other posttranscriptional mechanisms such as an increase in UCP1 translation may explain the observation of higher UCP1 protein than mRNA levels after icing; notably, we made a similar observation on TMEM26 mRNA and protein expression. Other factors may contribute to the induction of beiging in obese humans. For instance, there have been studies that suggest that the SNS is activated by hyperinsulinemia that occurs with obesity (35-39), and this may promote induction of UCP1 protein expression to counter obesity. SNS activation by hyperinsulinemia could also contribute to the increase in TMEM26 observed in the cold-treated leg of obese subjects, which inversely correlated with BMI and insulin resistance. 
A

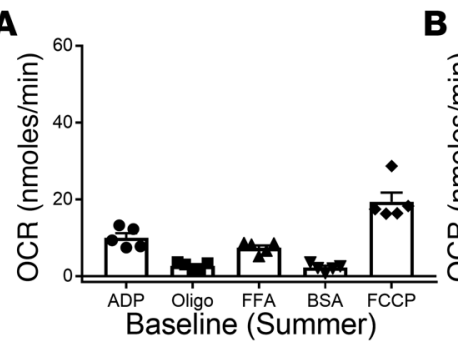

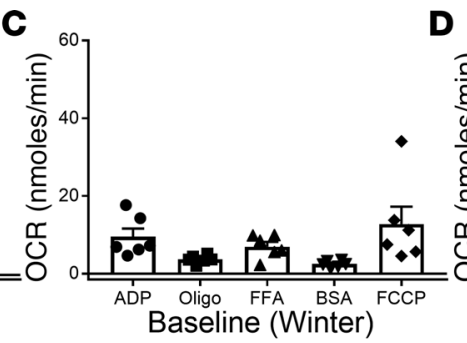

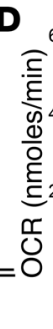

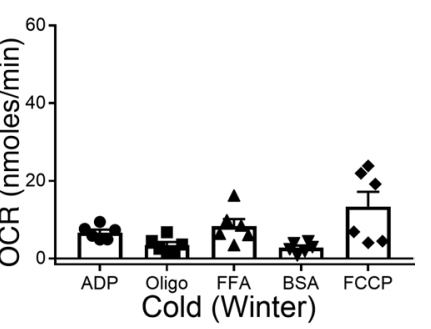

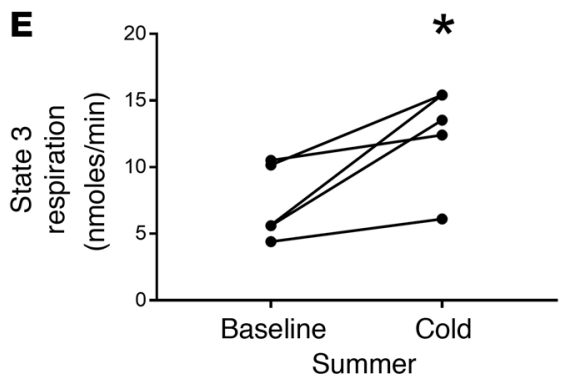
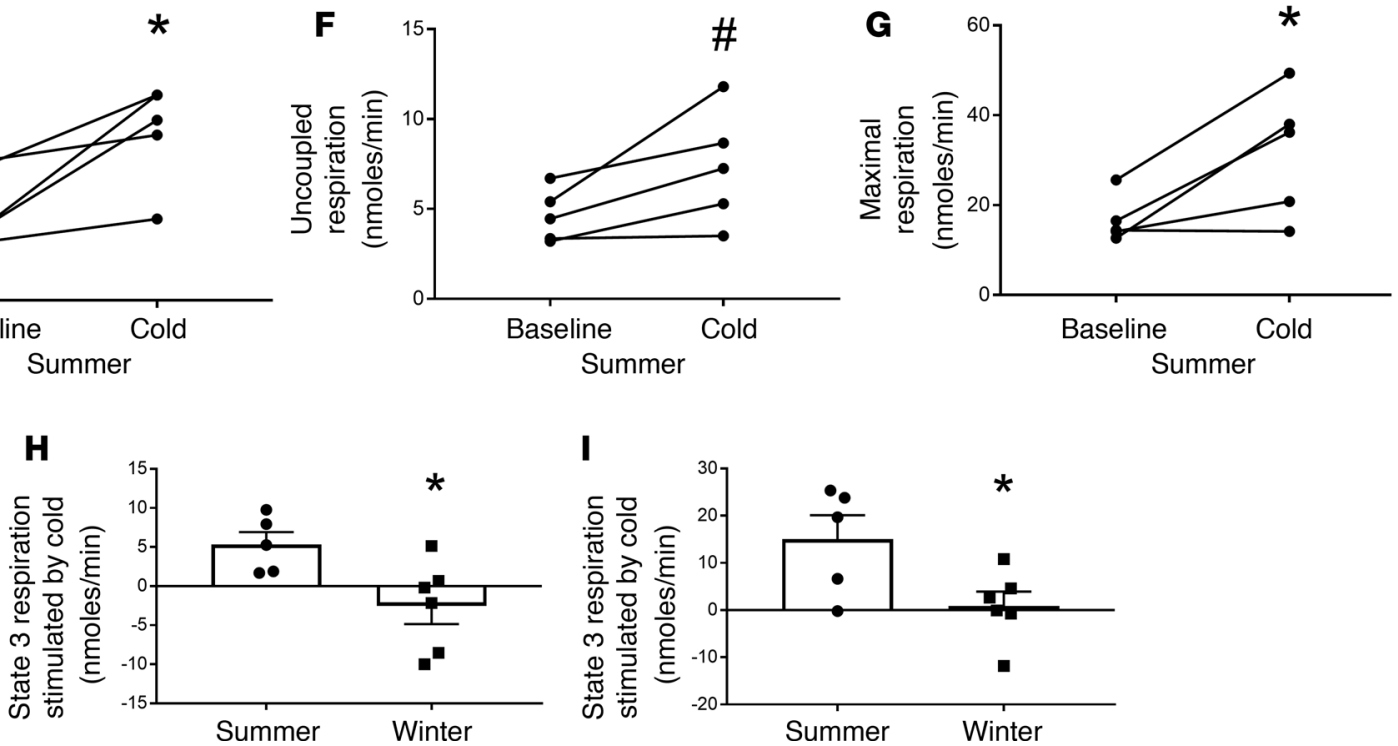

Figure 6. Cold changes mitochondrial bioenergetics more in the summer than winter. The oxygen consumption rate (OCR) data from Figure 5 were analyzed by season. (A and B) Mitochondrial bioenergetics at baseline and after cold in the summer $(n=5)$. (C and $\mathbf{D})$ Mitochondrial bioenergetics at baseline and after cold in the winter $(n=6)$. (E-C) The baseline and cold OCRs for State 3 respiration, uncoupling protein-mediated uncoupled respiration, and maximal uncoupled respiration at baseline and in response to cold in the summer; these values were calculated as described in Figure 5 . (H and I) The change (cold-baseline) in State 3 and maximal OCRs stimulated by cold in summer and winter. Data are represented as mean \pm SEM. The data were analyzed by a paired, 2-tailed student's $t$ test; ${ }^{*} P<0.05 ;{ }^{\#} P<0.1$.

Many studies have found that inducible BAT is diminished with aging $(20,22,40,41)$, and a recent in vitro study demonstrated that human adipose tissue stromal vascular cells from older subjects do not beige as well as those from younger subjects (42). Therefore, it was somewhat unexpected that the induction of UCP1 and TMEM26 was not inversely correlated with age. From studies of beige adipose formation in rodents, Kajimura and colleagues have postulated that, in the absence of stimulation, beige adipocytes hide or are masked in WAT depots and reveal themselves rapidly after stimulation (1). Our results would indicate that beige adipocytes may be able to hide for very long periods of time during aging or the development of obesity in humans.

The results of our mitochondrial bioenergetics experiments indicate that cold increases FFA-mediated uncoupling and maximal respiration. Furthermore, this response is greater in the summer than winter. This increase in responsiveness in the summer is possibly due to continuous seasonal exposure to cold in the winter, dampening the response to repeated icing. Seasonal exposure to cold would be predicted to increase baseline uncoupling; however, as shown in Figure 6, baseline uncoupling was not higher in the winter, and stimulation of uncoupling by cold was not as strong in the winter. UCP1 activity is regulated in a complex manner beyond protein expression levels. For instance, reactive oxygen species render UCP1 more sensitive to $\beta$-adrenergic stimulation (43), and CIDEA inhibits UCP1 activity by an undefined mechanism (44). It will be important to determine whether these are regulated by acute cold and by season in s.c. WAT in the future. We also note that summer and winter subjects were not the same; a paired study design may allow us to detect seasonal changes in the future. Since mitochondrial dysfunction is postulated to contribute to adipose dysfunction in obesity (45-47), it will be important to determine whether cold has similar effects on mitochondrial bioenergetics in obese humans. Finally, it is important to consider that cells other than 

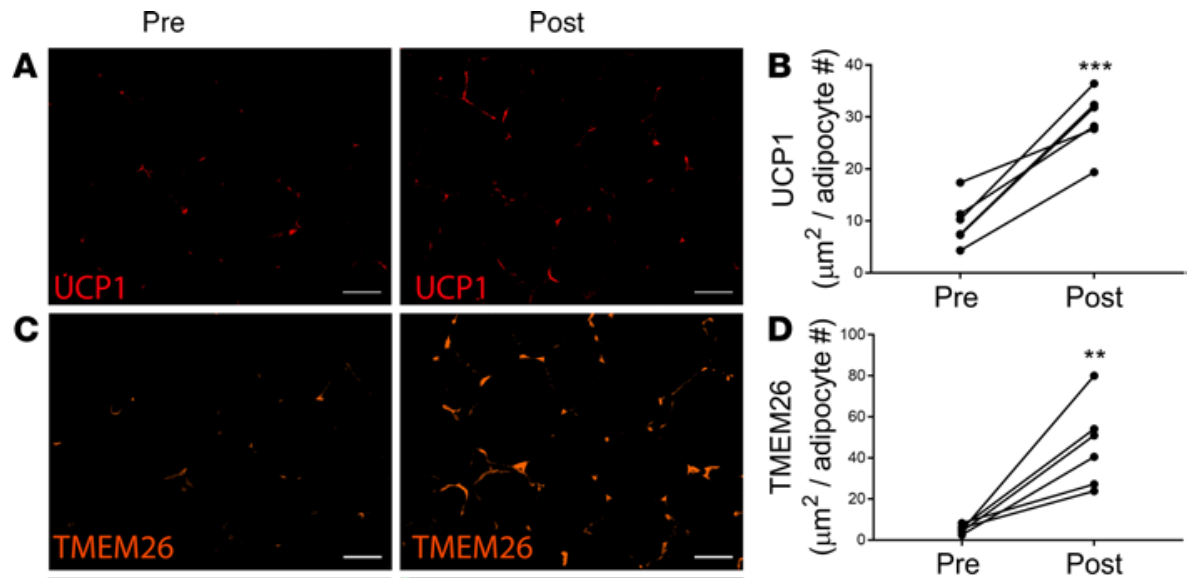

E
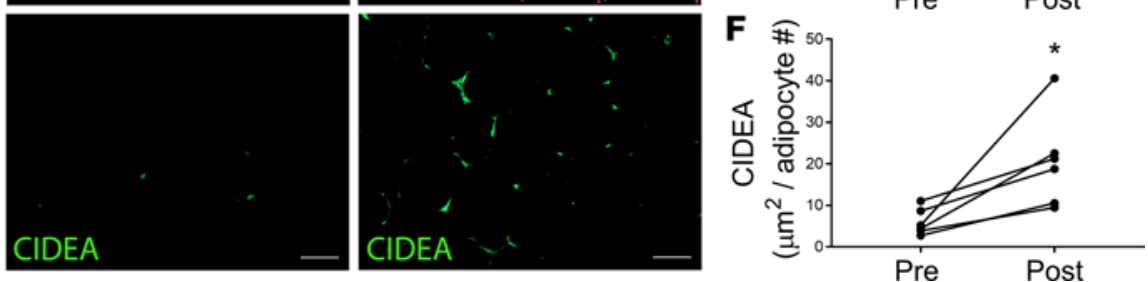

Figure 7. Mirabegron treatment induces beige adipocyte markers in obese subjects. S.c. white adipose tissue (WAT) was isolated from obese subjects before and after treatment with $50 \mathrm{mg}$ mirabegron per day for 10 weeks. (A and B) Uncoupling protein 1 (UCP1), (C and D) transmembrane protein 26 (TMEM26), and (E and F) cell death-inducing DNA fragmentation factor- $\alpha$-like effector A (CIDEA) were analyzed by IHC as described in Methods and quantified. Scale bars: $50 \mu \mathrm{m}$. Data represent mean $\pm \operatorname{SEM}(n=6)$ and were analyzed by a paired, 2-tailed student's $t$ test; ${ }^{* * *} P<0.001$; ${ }^{*} P<0.01 ;{ }^{*} P<0.05$.

adipocytes, such as endothelial cells, express UCP1. This may have some impact on the mitochondrial bioenergetics in this study of whole adipose tissue.

Stimulation of the $\beta 3$ receptor has long been postulated to have beneficial metabolic effects in obesity. In past clinical trials, there was difficulty in obtaining selective $\beta 3$ compounds (side effects observed were tremor and tachycardia from $\beta 1$ crossover effects) and with bioavailability $(48,49)$; however, several relatively specific $\beta 3$ drugs have been used in human trials. Initially, body weight reduction and increased resting metabolic rate were expected outcomes, and results were usually disappointing $(50,51)$. However, CL-316,243 treatment of lean subjects increased glucose disposal and decreased respiratory quotient, which preceded any weight loss (52). Mirabegron was developed as a specific $\beta 3$ agonist for the treatment of overactive bladder at a clinically indicated dose of 25 or $50 \mathrm{mg} /$ day. A recent review summarized multiple phase II and III studies and confirms the generally excellent cardiovascular safety record of mirabegron (53). At higher doses of 100 and $200 \mathrm{mg} /$ day, there were significant increases in pulse or blood pressure, but these effects were generally asymptomatic and not associated with cardiovascular outcomes $(53,54)$. It should be noted that the target population of patients with overactive bladder are mostly older women (mean age 57; ref. 54), who would be susceptible to cardiovascular side effects, and hence similar to the population that would theoretically be treated with a $\beta 3$ agonist for metabolic syndrome.

Mirabegron treatment for 10 weeks clearly increased beige adipose UCP1, TMEM26, and CIDEA protein expression and HSL serine ${ }^{660}$ phosphorylation in this cohort of obese, insulin-resistant subjects. The increase in UCP1 by mirabegron was approximately 1.5 -fold more than in our 10-day repeated cold study. PGC1 $\alpha$ was not induced by mirabegron. We and others $(1,19)$ have shown that inflammatory cytokines and TGF $\beta$ inhibit PGC1 $\alpha$ expression. It is possible that the increased number of macrophages in obese adipose tissue $(55,56)$ inhibit the induction of PGC1 $\alpha$ by $\beta$-adrenergic receptor activation, limiting the beiging response. Consistent with this idea, we have shown that $P G C 1 \alpha$ mRNA expression is induced by cold in lean subjects rapidly (4 hours) after the stimulus (19). Future studies will determine whether longer-term treatment or the combination of a $\beta 3$ agonist with diet or other drugs will increase PGC1 $\alpha$ expression to further promote beiging.

In summary, human s.c. WAT clearly increases protein expression of beige adipose markers in response to cold, and this is not associated with BMI, insulin resistance, or age. The finding that exposing a small 
A

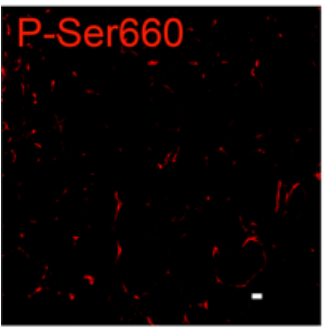

Pre

D

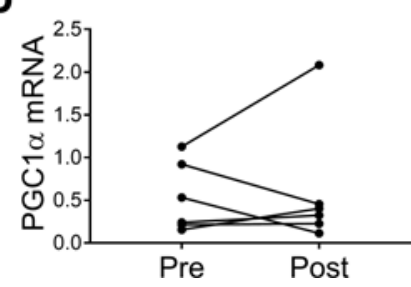

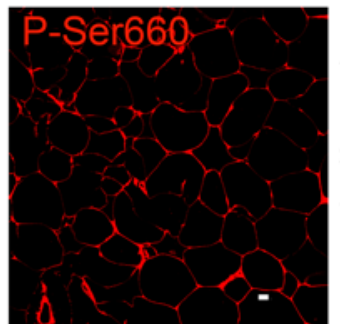

B

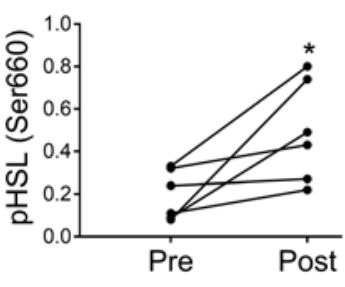

C

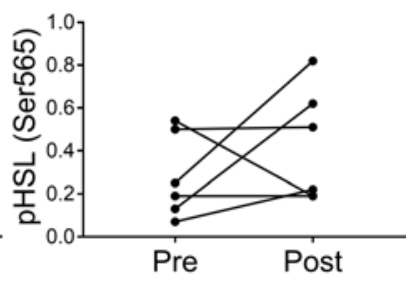

Post
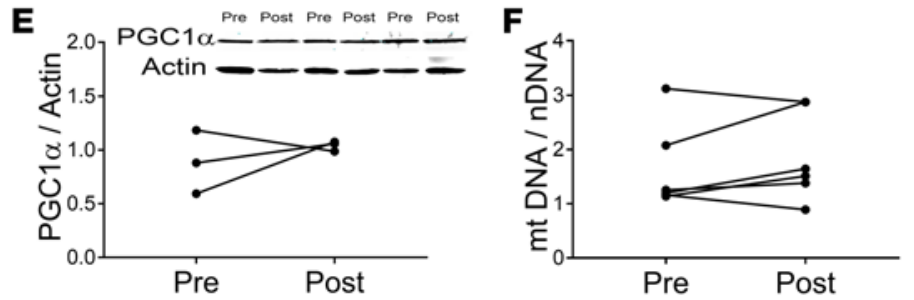

Figure 8. Mirabegron treatment increases hormone sensitive lipase (HSL) serine ${ }^{660}$ (P-Ser660) phosphorylation but does not induce peroxisome proliferator-activated receptor $\gamma$ coactivator 1- $\alpha$ (PGC1 $\alpha$ ) expression. (A and B) HSL phosphorylation on residue serine ${ }^{660}$ was characterized in abdominal s.C. white adipose tissue (WAT)before and after mirabegron treatment by IHC and quantified as described in Methods. Scale bars: $10 \mu \mathrm{M}$. (C) HSL phosphorylation on serine ${ }^{565}$ was determined by IHC. (D) PGC1A mRNA expression was determined by quantitative PCR as described in Methods. (E) PGC1 $\alpha$ protein expression was determined by immunoblotting as described in Methods. Inset, PGC1 $\alpha$ and actin immunoblots (uncropped blots are shown in Supplemental Figure 3). (F) The mitochondrial DNA/nuclear DNA ratio was determined as described in Methods. The data represent mean \pm SEM. The data in B-F were analyzed by a paired student's, 2-tailed $t$ test $\left(n=6\right.$, except $\left.\mathbf{E}[n=3] ;{ }^{*} P<0.05\right)$.

surface area of skin induces a whole-body response is a potentially novel finding. Furthermore, the observation that s.c. WAT beiging in response to cold is not reduced in older or obese, insulin-resistant subjects was unexpected. Mirabegron also induces the expression of beige adipose markers. Future studies will determine whether adipose beiging and mirabegron treatment are related to improved glucose and lipid homeostasis.

\section{Methods}

Human subjects and study design. Subjects were recruited from the Lexington, Kentucky (USA), area in the summer (June 1 and September 15; mean temperature $20^{\circ} \mathrm{C}-24^{\circ} \mathrm{C}$ ) and the winter (December 1 and March 21; mean temperature $4^{\circ} \mathrm{C}-8^{\circ} \mathrm{C}$ ) as indicated. No subjects worked outdoors. All subjects had baseline bloodwork, which included thyroid testing, and all were normal. To determine the effect of cold on s.c. WAT beiging, lean $(\mathrm{BMI}<27)$ and obese $(\mathrm{BMI}>30)$ research participants were studied. $\mathrm{S}_{\mathrm{I}}$ (Matsuda Index) was determined before the study, as described (57). Baseline biopsies of thigh fat were obtained in the morning from fasting subjects as described (18). The research participants then applied an ice pack to their thigh for 30 minutes each day for 10 consecutive days, and on the next morning, a thigh adipose biopsy was performed on the iced leg and the contralateral leg. A subset of lean subjects also had abdominal biopsies, which were used to obtain mitochondria; these subjects applied an ice pack to one side of their abdomen for 10 consecutive days in addition to icing their thigh. To determine the effect of the $\beta 3$ agonist mirabegron on s.c. WAT beiging, obese (BMI > 30) research participants were studied. Baseline s.c. WAT biopsies were performed on the abdomen before and after 10 weeks of mirabegron treatment ( $50 \mathrm{mg} /$ day). Research participants were not blinded to the intervention.

IHC on adipose tissue. IHC on UCP1, TMEM26, and CIDEA expression was performed as described (18). We did not quantify staining in fibrotic areas. Sections from the same person were always stained simultaneously, and images were obtained using similar exposure times for all sections. The area stained by a particular antibody was assessed using a thresholding feature of Zeiss software (Axiovision) and was normalized to adipocyte number since we studied both lean and obese subjects, which have different adipocyte sizes. To ensure the specificity of the UCP1 antibody, we used 2 controls: (a) a negative control was processed without no primary antibody, and (b) UCP1 peptide inhibition was performed by incubating the antibody with peptide used to make the UCP1 antibody for 30 minutes before applying it to the tissue section. Incubation with UCP1 peptide completely inhibited UCP1 staining (Supplemental Figure 4). IHC on phospho-HSL serine ${ }^{660}$, phospho-HSL serine ${ }^{565}$, perilipin, and endothelial cells was performed as follows. Tissue samples were incubated 
with blocking serum (10\% normal goat serum for 3 hours at room temperature) and with specific primary antisera overnight. Samples were rinsed and incubated with biotinylated goat anti-rabbit antibody (Jackson ImmunoResearch, catalog 11-065-003), rinsed and incubated with Strepavidin-HRP \#S911,Life Technologies), and rinsed and incubated with AlexaFluor 594 tyramide reagent (Invitrogen, catalog B40957). Specificity of stains was assessed from samples incubated with secondary antibodies alone. Nuclei were stained by mounting in ProLong Gold Antifade Reagent with DAPI. For pHSL staining, sections were visualized on a confocal microscope (BioRad MRC1024). For fluorescent intensity assessment, at least 3 independent fields were obtained for each human sample, and signal was quantified using open source Fiji image processing package (https://loci.wisc.edu/software/fiji). In each case, the specific signal was normalized to the signal from lipid droplet-associated perilipin. The catalog numbers of the antibodies are as follows: UCP1 (ab10983, Abcam); custom antibody to the same UCP1 peptide (residues 145-159) was from ECM Biosciences (catalog J2648); TMEM26 (NBP2-27334, Novus Biologicals); CIDEA (H00001149-M01, Novus Biologicals); CD31 (8306, Santa Cruz Biotechnology Inc.); Lectin from Ulex europaeus TRITC conjugate (L4889, MilliporeSigma); phospho-HSL (serine ${ }^{565}, 4137$; serine ${ }^{660}, 4126$, Cell Signaling Technology); perilipin-Alexa Fluor 488 conjugate (Novus Biologicals, catalog NB110-40760AF488). Wheat germ agglutinin Alexa Fluor 633 (catalog W21404) conjugate and goat anti-rabbit Alexa Fluor 546 (catalog A11035) were from Thermo Fisher Scientific. Normal goat serum was obtained from Jackson ImmunoResearch Laboratories, and ProLong Gold Antifade Reagent with DAPI was from Invitrogen.

$m R N A$ quantification. mRNA purification and quantitative PCR was performed using a standard curve as described (18). Gene expression was normalized to the expression of the geometric mean of 6 housekeeping genes; the primer sequences of UCP1, TMEM26, PGC1 $\alpha$, and the housekeeping genes are listed in Supplemental Table 3.

$m t D N A$. The ratio of mtDNA to nuclear DNA (nDNA) was determined by real-time PCR. DNA from abdominal s.c. adipose was purified with a DNeasy Blood \& Tissue Kit (Qiagen, catalog 69504). Primers were designed with Primer-BLAST/BLAST (National Center for Biotechnology Information). Real-time PCR of 6 targets (3 mitochondrial, 3 nuclear) was performed using Sybrgreen qPCR assay on the Quant Studio 3 RealTime PCR System (Applied Biosystems) using the following thermal profile: $95^{\circ} \mathrm{C}$ for 10 minutes; 40 cycles of $95^{\circ} \mathrm{C}$ for 15 seconds, $55^{\circ} \mathrm{C}$ for 15 seconds. Absolute quantification was obtained using a standard curve. The ratio of $\mathrm{mtDNA} / \mathrm{nDNA}$ was calculated by dividing the geometric mean of MT-ND1, MT-ND4, and MT-ND6 by the geometric mean of BECN1, CYPB, and NEB1. The primer sequences are listed in Supplemental Table 3.

Immunoblotting. Adipose tissue $(50 \mathrm{mg}$ ) was lysed in $100 \mu \mathrm{RIPA}$ buffer (50 mM Tris, $150 \mathrm{mM} \mathrm{NaCl}$, $0.1 \%$ SDS, $0.5 \%$ Sodium Deoxycholate, and 1\% IGEPAL CA-630) with $1 \times$ protease inhibitors (Calbiochem) by sonication. The lysate was then centrifuged at $1,000 \mathrm{~g}$ for 10 minutes at $4^{\circ} \mathrm{C}$ to remove cellular debris. Lysate $(50 \mu \mathrm{g})$ was resolved on a 10\% SDS-PAGE gel, transferred to nitrocellulose, and immunoblotted as follows. The membranes were blocked in Tris buffered saline (TBS: $20 \mathrm{mM}$ Tris pH 8.0, and $150 \mathrm{mM} \mathrm{NaCl}$ ) with $1 \%$ casein, incubated with IRDye $800 \mathrm{CW}$ donkey anti-rabbit secondary antibodies (925-32213, LI-COR Biosciences) for 1 hour, washed 3 times with TBS, and quantified using an Odyssey imaging system (LI-COR Biosciences). Antibodies against PGC1 $\alpha$ (NBP1-04676, Novus Biologicals) were used at a 1:1,000 dilution. Antibodies against actin (used as a loading control) were from MilliporeSigma (A1978) and used at a 1:10,000 dilution.

Isolation of mitochondria from human adipose tissue. The mitochondrial isolation technique was adapted from $(58,59)$ and carried out on ice or at $4^{\circ} \mathrm{C}$. Abdominal s.c. WAT $(3-4 \mathrm{~g})$ was placed immediately in $25 \mathrm{ml}$ ice-cold mitochondrial isolation buffer (MIB, $215 \mathrm{mM}$ mannitol, $75 \mathrm{mM}$ sucrose, 0.1 \% BSA, $1 \mathrm{mM}$ EGTA, $20 \mathrm{mM}$ HEPES, $\mathrm{pH}$ 7.2). The tissue was finely minced using scissors, divided into 3 equal parts, and homogenized in $4 \mathrm{ml} \mathrm{MIB}$ at $200 \mathrm{rpm}$ (8-10 times up and down) using a motorized Glass/Teflon Potter Elvehjem homogenizer. The homogenates were pooled and centrifuged at 1,300 $\mathrm{g}$ for 3 minutes. The top fat layer was carefully removed, and the supernatant was distributed into 2-ml tubes. The tubes were centrifuged at 1,300 $\mathrm{g}$ for 3 minutes, and the supernatant was then removed and centrifuged at 13,000 $\mathrm{g}$ for 10 minutes. The supernatants were discarded, and all the pellets were combined, resuspended in $\mathrm{MIB}$, and centrifuged at 13,000 $\mathrm{g}$ for 10 minutes, and the supernatant was discarded. The mitochondrial pellets were suspended in MIB without EGTA to achieve a concentration greater than $10 \mathrm{mg} / \mathrm{ml}$, and the protein content was measured using a BCA kit (Thermo Fischer Scientific, catalog 23227) according to the manufacturer's instructions.

Mitochondrial bioenergetics. Mitochondrial bioenergetics were assessed using an Oxytherm System (Hansatech Instruments) as previously described $(60,61)$. Briefly, mitochondria equivalent to $150 \mu \mathrm{g}$ of 
mitochondrial protein were added to the Oxytherm chamber containing $250 \mu 1$ mitochondrial respiration buffer (125 mM KCl, $2 \mathrm{mM} \mathrm{MgCl}_{2}, 2.5 \mathrm{mM} \mathrm{KH}_{2} \mathrm{PO}_{4}, 20 \mathrm{mM} \mathrm{HEPES}, \mathrm{pH}$ adjusted to 7.2 ) at $37^{\circ} \mathrm{C}$ under constant stirring. Complex I-mediated respiration (NADH-driven) was initiated by adding pyruvate and malate ( $5 \mathrm{mM}$ and $2.5 \mathrm{mM}$, respectively) followed by addition of ADP (300 $\mu \mathrm{M}$ final in 2 steps) to induce State 3 respiration. The ATP synthase activity was then inhibited by the addition of $2.5 \mu \mathrm{M}$ Oligo to induce State 4 respiration. Uncoupling protein-driven respiration was induced by addition of $60 \mu \mathrm{M}$ linoleic acid. To shut down uncoupling, fatty acid free BSA $(3 \%)$ was added to sequester FFA. Finally, maximum respiration was measured in the presence of $10 \mu \mathrm{M}$ trifluoromethoxy carbonylcyanide phenylhydrazone (FCCP). The OCRs were determined and are expressed as nanomoles $/ \mathrm{min}$. Uncoupled respiration was defined as the difference between FFA-induced respiration and State 4 respiration, and maximal respiration was defined as the difference between FCCP-induced respiration and State 4 respiration.

Statistics. Analyses of the induction of beige adipocyte markers presented in Figure 1, Figure 2, and Supplemental Figure 1 were conducted via the use of multivariate Gaussian linear models with unstructured working covariance, and inference was conducted using $t$ tests and the Kenward and Roger adjustment for standard error estimation and degrees of freedom calculation. This approach is analogous to repeated-measures multivariate ANOVA (MANOVA) and accounts for the statistical correlation among the 3 outcomes from each subject. Spearman correlations were used to assess associations of outcomes with age and BMI. Outcomes were also categorized by sex. Wilcoxon exact tests were used to test for differences between males and females. Analyses were conducted in SAS version 9.4 (SAS Institute). Paired Student's $t$ tests and Mann-Whitney $U$ tests were performed where indicated in Graphpad Prism version 7.0. We identified an outlier in the obese group who had very high baseline expression of UCP1 and removed the subject from the study. All tests were 2-sided, and statistical significance for all tests was set at $P \leq 0.05$.

Study approval. All subjects gave informed consent, and the protocols were approved by the IRB at the University of Kentucky.

\section{Author contributions}

PAK, EEDV, PGS, CMA, and BSF designed the experiments, analyzed data, and wrote the manuscript. BZ, HM, ALC, IK, BH, KAJ, ZRJ, and HJV performed the experiments. PMW analyzed data.

\section{Acknowledgments}

We wish to thank the staff of the University of Kentucky Clinical Research Unit for the assistance with this study and Dorothy Ross for coordinating the recruitment of the participants. This work was funded with the following NIH grants: DK107646, DK112282, P20GM103527, and by CTSA grant UL1TR001998.

Address correspondence to: Philip A. Kern, Division of Endocrinology, CTW 521, University of Kentucky, 900 S. Limestone Street, Lexington, Kentucky 40536, USA. Phone: 859.218.1394; Email: philipkern@uky.edu.

1. Kajimura S, Spiegelman BM, Seale P. Brown and Beige Fat: Physiological Roles beyond Heat Generation. Cell Metab. 2015;22(4):546-559.

2. Wu J, et al. Beige adipocytes are a distinct type of thermogenic fat cell in mouse and human. Cell. 2012;150(2):366-376.

3. Sidossis L, Kajimura S. Brown and beige fat in humans: thermogenic adipocytes that control energy and glucose homeostasis. J Clin Invest. 2015;125(2):478-486.

4. Rothwell NJ, Stock MJ. A role for brown adipose tissue in diet-induced thermogenesis. Nature. 1979;281(5726):31-35.

5. Lowell BB, et al. Development of obesity in transgenic mice after genetic ablation of brown adipose tissue. Nature. 1993;366(6457):740-742.

6. Feldmann HM, Golozoubova V, Cannon B, Nedergaard J. UCP1 ablation induces obesity and abolishes diet-induced thermogenesis in mice exempt from thermal stress by living at thermoneutrality. Cell Metab. 2009;9(2):203-209.

7. Porter C, Chondronikola M, Sidossis LS. The Therapeutic Potential of Brown Adipocytes in Humans. Front Endocrinol (Lausanne). 2015;6:156.

8. Stanford KI, et al. Brown adipose tissue regulates glucose homeostasis and insulin sensitivity. J Clin Invest. 2013;123(1):215-223.

9. Cohen P, et al. Ablation of PRDM16 and beige adipose causes metabolic dysfunction and a subcutaneous to visceral fat switch. Cell. 2014;156(1-2):304-316.

10. Chondronikola M, et al. Brown adipose tissue improves whole-body glucose homeostasis and insulin sensitivity in humans. Diabetes. 2014;63(12):4089-4099.

11. Orava J, et al. Different metabolic responses of human brown adipose tissue to activation by cold and insulin. Cell Metab. 2011;14(2):272-279.

12. Matsushita M, Yoneshiro T, Aita S, Kameya T, Sugie H, Saito M. Impact of brown adipose tissue on body fatness and glucose 
metabolism in healthy humans. Int J Obes (Lond). 2014;38(6):812-817.

13. Ouellet $\mathrm{V}$, et al. Brown adipose tissue oxidative metabolism contributes to energy expenditure during acute cold exposure in humans. J Clin Invest. 2012;122(2):545-552.

14. Lee P, Greenfield JR, Ho KK, Fulham MJ. A critical appraisal of the prevalence and metabolic significance of brown adipose tissue in adult humans. Am J Physiol Endocrinol Metab. 2010;299(4):E601-E606.

15. Min SY, et al. Human 'brite/beige' adipocytes develop from capillary networks, and their implantation improves metabolic homeostasis in mice. Nat Med. 2016;22(3):312-318.

16. Asterholm IW, Mundy DI, Weng J, Anderson RG, Scherer PE. Altered mitochondrial function and metabolic inflexibility associated with loss of caveolin-1. Cell Metab. 2012;15(2):171-185.

17. Hanssen MJ, et al. Short-term cold acclimation improves insulin sensitivity in patients with type 2 diabetes mellitus. Nat Med. 2015;21(8):863-865.

18. Finlin BS, et al. Mast Cells Promote Seasonal White Adipose Beiging in Humans. Diabetes. 2017;66(5):1237-1246.

19. Kern PA, et al. The effects of temperature and seasons on subcutaneous white adipose tissue in humans: evidence for thermogenic gene induction. J Clin Endocrinol Metab. 2014;99(12):E2772-E2779.

20. Cypess AM, et al. Identification and importance of brown adipose tissue in adult humans. NEngl J Med. 2009;360(15):1509-1517.

21. van Marken Lichtenbelt WD, et al. Cold-activated brown adipose tissue in healthy men. NEngl J Med. 2009;360(15):1500-1508.

22. Saito M, et al. High incidence of metabolically active brown adipose tissue in healthy adult humans: effects of cold exposure and adiposity. Diabetes. 2009;58(7):1526-1531.

23. Stanford KI, Goodyear LJ. Exercise regulation of adipose tissue. Adipocyte. 2016;5(2):153-162.

24. Sidossis LS, et al. Browning of Subcutaneous White Adipose Tissue in Humans after Severe Adrenergic Stress. Cell Metab. 2015;22(2):219-227.

25. Petruzzelli M, et al. A switch from white to brown fat increases energy expenditure in cancer-associated cachexia. Cell Metab. 2014;20(3):433-447.

26. Frontini A, et al. White-to-brown transdifferentiation of omental adipocytes in patients affected by pheochromocytoma. Biochim Biophys Acta. 2013;1831(5):950-959.

27. Kir S, et al. Tumour-derived PTH-related protein triggers adipose tissue browning and cancer cachexia. Nature. 2014;513(7516):100-104.

28. Cypess AM, et al. Activation of human brown adipose tissue by a $\beta 3$-adrenergic receptor agonist. Cell Metab. 2015;21(1):33-38.

29. Tiraby C, et al. Acquirement of brown fat cell features by human white adipocytes. J Biol Chem. 2003;278(35):33370-33376.

30. Kleiner S, et al. Development of insulin resistance in mice lacking PGC-1 $\alpha$ in adipose tissues. Proc Natl Acad Sci USA. 2012;109(24):9635-9640.

31. Cao W, et al. p38 mitogen-activated protein kinase is the central regulator of cyclic AMP-dependent transcription of the brown fat uncoupling protein 1 gene. Mol Cell Biol. 2004;24(7):3057-3067.

32. Allan R, et al. Postexercise cold water immersion modulates skeletal muscle PGC-1 $\alpha$ mRNA expression in immersed and nonimmersed limbs: evidence of systemic regulation. J Appl Physiol. 2017;123(2):451-459.

33. Ye L, et al. Fat cells directly sense temperature to activate thermogenesis. Proc Natl Acad Sci USA. 2013;110(30):12480-12485.

34. Gospodarska E, Nowialis P, Kozak LP. Mitochondrial turnover: a phenotype distinguishing brown adipocytes from interscapular brown adipose tissue and white adipose tissue. J Biol Chem. 2015;290(13):8243-8255.

35. Schlaich M, Straznicky N, Lambert E, Lambert G. Metabolic syndrome: a sympathetic disease? Lancet Diabetes Endocrinol. 2015;3(2):148-157.

36. Thorp AA, Schlaich MP. Relevance of Sympathetic Nervous System Activation in Obesity and Metabolic Syndrome. J Diabetes Res. 2015;2015:341583.

37. Reaven G. The metabolic syndrome or the insulin resistance syndrome? Different names, different concepts, and different goals. Endocrinol Metab Clin North Am. 2004;33(2):283-303.

38. Facchini FS, Stoohs RA, Reaven GM. Enhanced sympathetic nervous system activity. The linchpin between insulin resistance, hyperinsulinemia, and heart rate. Am J Hypertens. 1996;9(10 Pt 1):1013-1017.

39. O'Hare JA, Minaker KL, Meneilly GS, Rowe JW, Pallotta JA, Young JB. Effect of insulin on plasma norepinephrine and 3,4-dihydroxyphenylalanine in obese men. Metab Clin Exp. 1989;38(4):322-329.

40. Yoneshiro T, et al. Age-related decrease in cold-activated brown adipose tissue and accumulation of body fat in healthy humans. Obesity (Silver Spring). 2011;19(9):1755-1760.

41. Pfannenberg C, et al. Impact of age on the relationships of brown adipose tissue with sex and adiposity in humans. Diabetes. 2010;59(7):1789-1793.

42. Berry DC, et al. Cellular Aging Contributes to Failure of Cold-Induced Beige Adipocyte Formation in Old Mice and Humans. Cell Metab. 2017;25(1):166-181.

43. Chouchani ET, et al. Mitochondrial ROS regulate thermogenic energy expenditure and sulfenylation of UCP1. Nature. 2016;532(7597):112-116.

44. Fischer AW, et al. UCP1 inhibition in Cidea-overexpressing mice is physiologically counteracted by brown adipose tissue hyperrecruitment. Am J Physiol Endocrinol Metab. 2017;312(1):E72-E87.

45. Kusminski CM, Scherer PE. Mitochondrial dysfunction in white adipose tissue. Trends Endocrinol Metab. 2012;23(9):435-443.

46. Boudina S, Graham TE. Mitochondrial function/dysfunction in white adipose tissue. Exp Physiol. 2014;99(9):1168-1178.

47. Schöttl T, Kappler L, Fromme T, Klingenspor M. Limited OXPHOS capacity in white adipocytes is a hallmark of obesity in laboratory mice irrespective of the glucose tolerance status. Mol Metab. 2015;4(9):631-642.

48. Villarroya F, Vidal-Puig A. Beyond the sympathetic tone: the new brown fat activators. Cell Metab. 2013;17(5):638-643.

49. Whittle A, Relat-Pardo J, Vidal-Puig A. Pharmacological strategies for targeting BAT thermogenesis. Trends Pharmacol Sci. 2013;34(6):347-355.

50. Redman LM, et al. Lack of an effect of a novel beta3-adrenoceptor agonist, TAK-677, on energy metabolism in obese individuals: a double-blind, placebo-controlled randomized study. J Clin Endocrinol Metab. 2007;92(2):527-531.

51. Arch JR. beta(3)-Adrenoceptor agonists: potential, pitfalls and progress. Eur J Pharmacol. 2002;440(2-3):99-107. 
52. Weyer C, Tataranni PA, Snitker S, Danforth E, Ravussin E. Increase in insulin action and fat oxidation after treatment with CL 316,243, a highly selective beta3-adrenoceptor agonist in humans. Diabetes. 1998;47(10):1555-1561.

53. Nitti VW, et al. Safety and tolerability of the $\beta 3$-adrenoceptor agonist mirabegron, for the treatment of overactive bladder: results of a prospective pooled analysis of three 12-week randomised Phase III trials and of a 1-year randomised Phase III trial. Int J Clin Pract. 2014;68(8):972-985.

54. Chapple CR, et al. A phase II dose-ranging study of mirabegron in patients with overactive bladder. Int Urogynecol J. 2013;24(9):1447-1458.

55. Spencer M, et al. Adipose tissue macrophages in insulin-resistant subjects are associated with collagen VI and fibrosis and demonstrate alternative activation. Am J Physiol Endocrinol Metab. 2010;299(6):E1016-E1027.

56. Di Gregorio GB, et al. Expression of CD68 and macrophage chemoattractant protein-1 genes in human adipose and muscle tissues: association with cytokine expression, insulin resistance, and reduction by pioglitazone. Diabetes. 2005;54(8):2305-2313.

57. Kern PA, et al. Effects of KDT501 on Metabolic Parameters in Insulin-Resistant Prediabetic Humans. J Endocr Soc. 2017;1(6):650-659.

58. Cannon B, Lindberg O. Mitochondria from brown adipose tissue: isolation and properties. Meth Enzymol. 1979;55:65-78.

59. Pandya JD, et al. Post-Injury Administration of Mitochondrial Uncouplers Increases Tissue Sparing and Improves Behavioral Outcome following Traumatic Brain Injury in Rodents. J Neurotrauma. 2007;24(5):798-811.

60. Sullivan PG, Dubé C, Dorenbos K, Steward O, Baram TZ. Mitochondrial uncoupling protein-2 protects the immature brain from excitotoxic neuronal death. Ann Neurol. 2003;53(6):711-717.

61. Sullivan PG, Rippy NA, Dorenbos K, Concepcion RC, Agarwal AK, Rho JM. The ketogenic diet increases mitochondrial uncoupling protein levels and activity. Ann Neurol. 2004;55(4):576-580. 